\title{
Enhanced expression and significance of glycosylphosphatidylinositol anchor attachment protein 1 in colorectal cancer
}

\author{
G. Chen ${ }^{1,2}$, S.Y. Li ${ }^{2}$, H.Y. Cai ${ }^{2}$ and F.Y. Zuo ${ }^{2}$ \\ ${ }^{1}$ Department of Postgraduate, Third Military Medical University, \\ Shapingba District, Chongqing, China \\ ${ }^{2}$ Department of General Surgery, \\ General Hospital of PLA Beijing Military Command, East District, Beijing, China \\ Corresponding author: S.Y. Li \\ E-mail: shiyong_li010@163.com
}

Genet. Mol. Res. 13 (1): 499-507 (2014)

Received August 26, 2013

Accepted October 28, 2013

Published January 21, 2014

DOI http://dx.doi.org/10.4238/2014.January.21.19

\begin{abstract}
The aim of this study was to investigate the expression of glycosylphosphatidylinositol anchor attachment protein 1 (GPAA1) and its significance in patients with colorectal cancer. Fifty-two patients with primary colorectal cancer were included in this study. GPAA1 expression was detected by immunohistochemistry, reverse transcriptionpolymerase chain reaction, and Western blot analysis. A cell invasion assay was performed by the transwell method. The interacting proteins of GPAA1 were detected by co-immunoprecipitation and matrix assisted laser desorption/ionization-time of flight mass spectrometry (MALDI-TOF/TOF-MS). The expression of GPAA1 mRNA and protein in primary colorectal tumor tissues and liver metastasis tissues was significantly higher than that in normal mucosa tissues $(\mathrm{P}<0.01)$. The number of highly expressing GPAA1 cells penetrating the Matrigel membrane was significantly higher than that of mildly expressing GPAA1 cells $(\mathrm{P}<0.05)$. The results of co-immunoprecipitation and MALDI-TOF/TOF-MS confirmed the identity of the protein. GPAA1
\end{abstract}


is highly expressed in patients with colorectal cancer, which indicates that it might play an important role in the proliferation, invasion, and metastasis of colorectal cancer.

Key words: GPAA1; Colorectal cancer; MALDI-TOF/TOF-MS; Co-immunoprecipitation

\section{INTRODUCTION}

We previously reported 10 proteins that interact with the FasL protein using proteomics techniques, including anchor attachment $(\mathrm{AN})$, metallothionein $1 \mathrm{~K}$, metallothionein $1 \mathrm{G}$, metallothionein $2 \mathrm{~A}$, cathepsin $\mathrm{B}$, fatty acid synthase, interferon alpha inducible protein 27, phospholipid scramblase, Ser/Thr-like kinase, and fiber microfilament protein-5 (Zuo et al., 2004, 2006). On the liver cell membrane, phosphatidylinositol was found to combine with AN to form glycosylphosphatidylinositol anchor attachment protein 1 (GPAA1), and the overexpression of GPAA1 was closely related to the occurrence and development of liver cancer (Ho et al., 2006). In this study, we detected the expression of GPAA1 in patients with colorectal cancer to explore the relationship between GPAA1 and the proliferation, invasion, and metastasis of colorectal cancer.

\section{MATERIAL AND METHODS}

\section{Source of specimens}

The primary colorectal cancer tissues of 52 patients were obtained from the General Surgery Department, General Hospital of Military Region, Beijing. None of the patients received preoperative radiochemotherapy, and their average age was 58.5 years. The primary colorectal tumor tissue, normal colorectal mucosa tissue, and liver metastasis tissue were removed quickly and stored in liquid nitrogen.

\section{Immunohistochemistry}

The mouse anti-human GPAA1 polyclonal antibody was purchased from Santa Cruz Biotechnology, and the antibody was diluted at 1:200 to obtain the working concentration. The streptomycin avidin-catalase method was used for immunohistochemical staining, and normal calf serum was used as the negative control. The results were determined as follows: no coloring cells, $-; 10-30 \%$ coloring cells, $+; 30-50 \%$ coloring cells, $++;>50 \%$ coloring cells, +++ . "-" and "+" were classified as negative expression, whereas "++" and "+++" were classified as positive expression.

\section{Real-time quantitative polymerase chain reaction (PCR)}

Total RNA was extracted with Trizol, and the primers were synthesized by Aoke Biological Technology Company with the following sequences: GPAA1-F (5'-TCT CAA GGC TCT GGA ACT G-3') and GPAA1-R (5'-GCC CCA CAC CCT GTG ATG-3'). The reference gene 
was 3-glyceraldehyde phosphate dehydrogenase (GAPDH). The reaction consisted of an initial denaturation step at $95^{\circ} \mathrm{C}$ for $5 \mathrm{~min}, 40$ thermal cycles, and an elongation step at $70^{\circ} \mathrm{C}$ for $7 \mathrm{~min}$. Each of the 40 thermal cycles consisted of a denaturing step at $95^{\circ} \mathrm{C}$ for $30 \mathrm{~s}$, an annealing step at $50^{\circ} \mathrm{C}$ for $30 \mathrm{~s}$, and an elongation step at $70^{\circ} \mathrm{C}$ for $30 \mathrm{~s}$. The relative expression of GPAA- 1 was calculated according to the formula: $2^{-\Delta \Delta \mathrm{Ct}}$, where $\Delta \Delta C t=[\mathrm{Ct}(\mathrm{GPAA} 1)-\mathrm{Ct}(\mathrm{GAPDH})]_{\text {experimental }}$ group $-[\mathrm{Ct}(\mathrm{GPAA} 1)-\mathrm{Ct}(\mathrm{GAPDH})]_{\text {control group }}$. Each sample was set in four replicate wells.

\section{Western blot}

One hundred milligrams primary colorectal tumor tissue, normal colorectal mucosa tissue, and liver metastasis tissue were ground in liquid nitrogen, and then the lysis buffer was added and the concentration of proteins was adjusted to $2.5 \mu \mathrm{g} / \mu \mathrm{L}$ with the bicinchoninic assay. Next, the proteins were boiled at $100^{\circ} \mathrm{C}$ for $5 \mathrm{~min}$, centrifuged at $12,000 \mathrm{~g}$ for $5 \mathrm{~min}$, and $50 \mu \mathrm{g}$ proteins were loaded. The electrophoresis conditions were as follows: the stacking gel was set at $80 \mathrm{~V}$ for $20 \mathrm{~min}$, and the separation gel was set at $100 \mathrm{~V}$. When bromophenol blue reached the bottom of the gel, semi-dry electrotransfer was performed (30 mA, $90 \mathrm{~min})$. After blocking, the GPAA-1 antibody was incubated overnight at $4{ }^{\circ} \mathrm{C}$, the membrane was washed with Tris-buffered saline with Tween, and incubated with horseradish peroxidase-labeled secondary antibody for $30 \mathrm{~min}$. The membrane was developed with ECL luminous liquid. Using the Image-Pro Plus software to analyze the gray scale of the GPAA- 1 and $\beta$-actin genes, the relative expression of the GPAA-1 protein was determined as the ratio of GPAA- 1 and $\beta$-actin gray scale.

\section{Cell invasion assay}

The primary cells of colorectal cancer tissues highly expressing GPAA1 (cell $1_{\text {High-GPAAl }}$ )

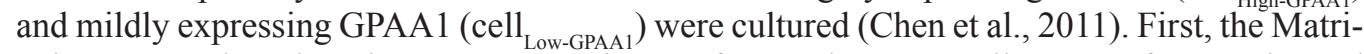
gel was coated on the microporous membrane of a Boyden transwell at $37^{\circ} \mathrm{C}$ for $30 \mathrm{~min}$, and then the transwell was placed on a 24 -well plate. Then, $0.4 \mathrm{~mL}\left(7.5 \times 10^{3}\right)$ cell $_{\text {High-GPAA1 }}$ and cell $_{\text {Low-GPAA } 1}$ were added to the upper chamber, and $0.6 \mathrm{~mL}$ medium was added to the lower chamber. There were 3 wells in each group. Cells were cultured with $5 \% \mathrm{CO}_{2}$ at $37^{\circ} \mathrm{C}$ for 72 $\mathrm{h}$, the membrane was removed and fixed with $75 \%$ methanol for 45 min, stained with hematoxylin overnight, and the number of cells penetrating the membrane was counted under a microscope. The number of cells penetrating the membrane without Matrigel was used as the control group (Negus and Balkwill, 1996).

\section{Detection of protein interacting with GPAA1 by co-immunoprecipitation}

The protein sample was diluted to $1 \mathrm{mg} / \mathrm{mL}$ with phosphate-buffered saline and placed on ice, $50 \%$ protein A-Agarose was added to incubate for $1 \mathrm{~h}$, centrifuged at $4^{\circ} \mathrm{C}$, the supernatant was collected, and $5 \mu \mathrm{g}$ GPAA1 antibody was added to incubate overnight at $4{ }^{\circ} \mathrm{C}$. Fifty microliters 50\% protein A-Agarose was added again, incubated on ice for $1 \mathrm{~h}$, centrifuged at $4^{\circ} \mathrm{C}$, and the supernatant was collected. Next, the protein A-Agarose-antibody-protein compound was washed three times with protein extraction reagent, denatured for $5 \mathrm{~min}$, and the supernatant was again collected by centrifugation. The unknown protein was detected by sodium dodecyl sulfate-polyacrylamide gel electrophoresis. The gel was stained with Coomassie Blue. 
Identification of unknown protein with matrix assisted laser desorption/ionizationtime of flight mass spectrometry (MALDI-TOF/TOF-MS)

The gel was cut into 1-2 $\mathrm{mm}^{3}$ sections, and then destained with solution containing $50 \%$ acetonitrile and $25 \mathrm{mM} \mathrm{NH}_{4} \mathrm{HCO}_{3}$. Next, the gel was dried in a vacuum centrifuge drier for 20 min, and trypsin solution was added to the gel at $37^{\circ} \mathrm{C}$ for $20 \mathrm{~h}$. The supernatant was collected after digestion, and then $50 \mu \mathrm{L} \mathrm{5 \%}$ trifluoroacetic acid (TFA) was added to the gel, incubated at $40^{\circ} \mathrm{C}$ for $1 \mathrm{~h}$, and the supernatant was collected again. Next, $20 \mu \mathrm{L} 5 \%$ TFA and $50 \mu \mathrm{L} 50 \%$ acetonitrile were added to the gel at $30^{\circ} \mathrm{C}$ for $1 \mathrm{~h}$, and the supernatant was collected again. Finally, all supernatants were merged together and dried by centrifugation. MALDI-TOF/TOF-MS was performed on an AB4700 mass spectrometer (Bruker Dalton) with the following settings: $20 \mathrm{kV}$, positive ions, CCA matrix, the internal standard used was the 2163.05 trypsin autotomy peak as calibration standards, and the external standard used was based on the mixture of seven standard peptides. The data were compared to the National Center for Biotechnology Information (NCBI) database with the Mascot software (http://www.matrixscience.co.uk).

\section{Statistical analysis}

The data were analyzed with the SPSS 13.0 software. For enumeration data, the $\chi^{2}$ test was used, and measurement data were analyzed with the Student $t$-test; $\mathrm{P}<0.05$ was considered to be statistically significant.

\section{RESULTS}

\section{Immunohistochemical detection}

Fifty-two colorectal cancer samples were subjected to immunohistochemistry, and GPAA1 was found to be located in the cytoplasm (Figure 1). The positive expression rate of GPAA1 in normal colorectal mucosa tissue, primary colorectal tumor tissue, and liver metastasis tissue were $21.15 \%$ (11/52), $55.76 \%(29 / 52)$, and $72.73 \%$ (8/11), respectively. The expression of GPAA1 in primary colorectal tumor tissues and liver metastasis tissues $\left(\chi^{2}=9.15\right)$ was significantly higher than that in normal mucosa tissue $\left(\chi^{2}=11.7406\right.$ and 9.1474, $\left.\mathrm{P}<0.01\right)$; there was no significant difference in the expression of GPAA1 between liver metastasis and tumor tissues $\left(\chi^{2}=0.4912, \mathrm{P}>0.05\right)$.

\section{Expression of the GPAA1 gene}

The results of real-time quantitative PCR showed that the expression of GPAA1 mRNA in primary colorectal tumor tissues $(13.76 \pm 7.451)$ and liver metastasis tissues $(19.32$ $\pm 11.243)$ was significantly higher than that in normal mucosa tissue $(6.24 \pm 4.768 ; t=3.5832$ and 3.6723, P $<0.01)$, and the expression of GPAA1 mRNA in liver metastasis tissues was higher than that in tumor tissues $(t=2.96, \mathrm{P}<0.05)$ (Figure 2).

\section{Expression of the GPAA1 protein}

The results of Western blot analysis showed that the molecular weight of GPAA1 was 
between 70 and $62 \mathrm{kDa}$. The expressions of the GPAA1 protein in primary colorectal tumor tissues $(1.112 \pm 0.240)$ and liver metastasis tissues $(1.482 \pm 0.342)$ were significantly higher than that in normal mucosa tissue $(0.434 \pm 0.106)(t=11.546$ and $12.066, \mathrm{P}<0.01)$, and the expression of the GPAA1 protein in liver metastasis tissues was higher than that in tumor tissues $(t=3.951, \mathrm{P}<0.01)$ (Figure 3).

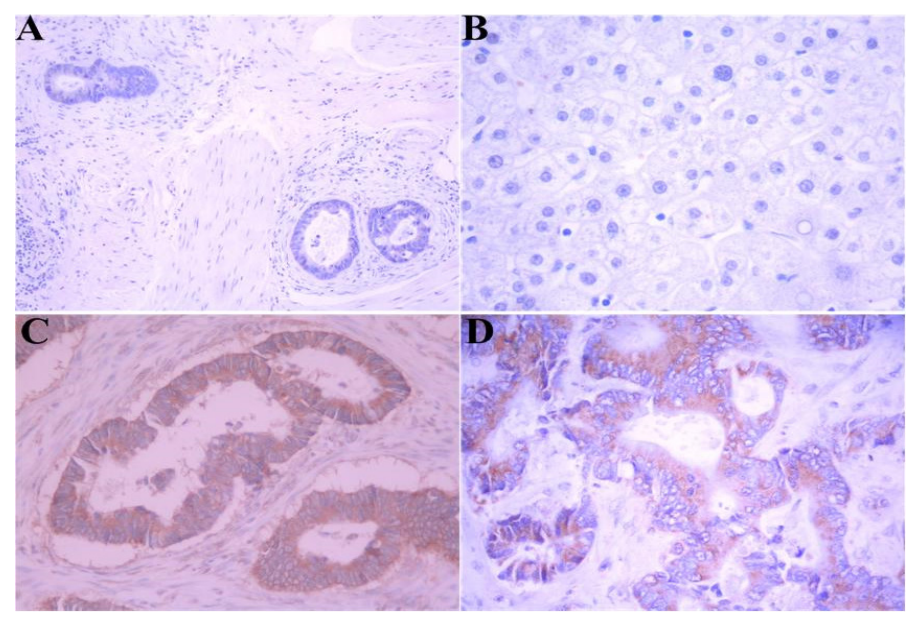

Figure 1. Immunohistochemical detection of GPAA1 in colorectal cancer. A. Normal colonic mucosa; B. normal liver; C. primary colorectal cancer; D. hepatic metastases.

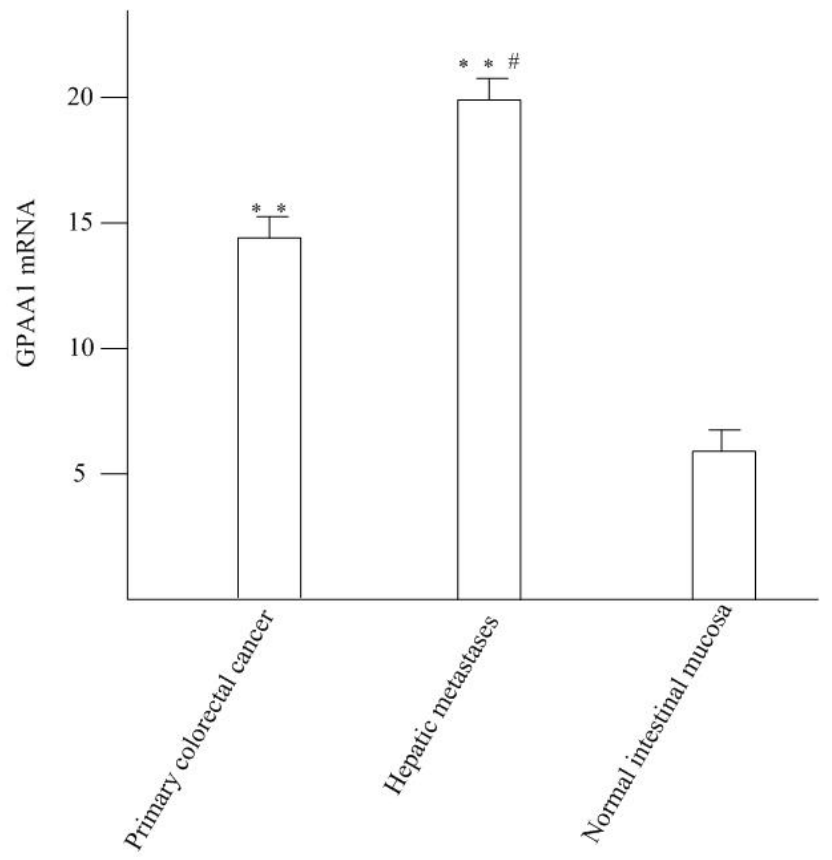

Figure 2. Expression of GPAA1 gene by RT-PCR. ${ }^{* *} \mathrm{P}<0.01$ compared to normal colonic mucosa. ${ }^{*} \mathrm{P}<0.05$ compared to primary colorectal cancer. 

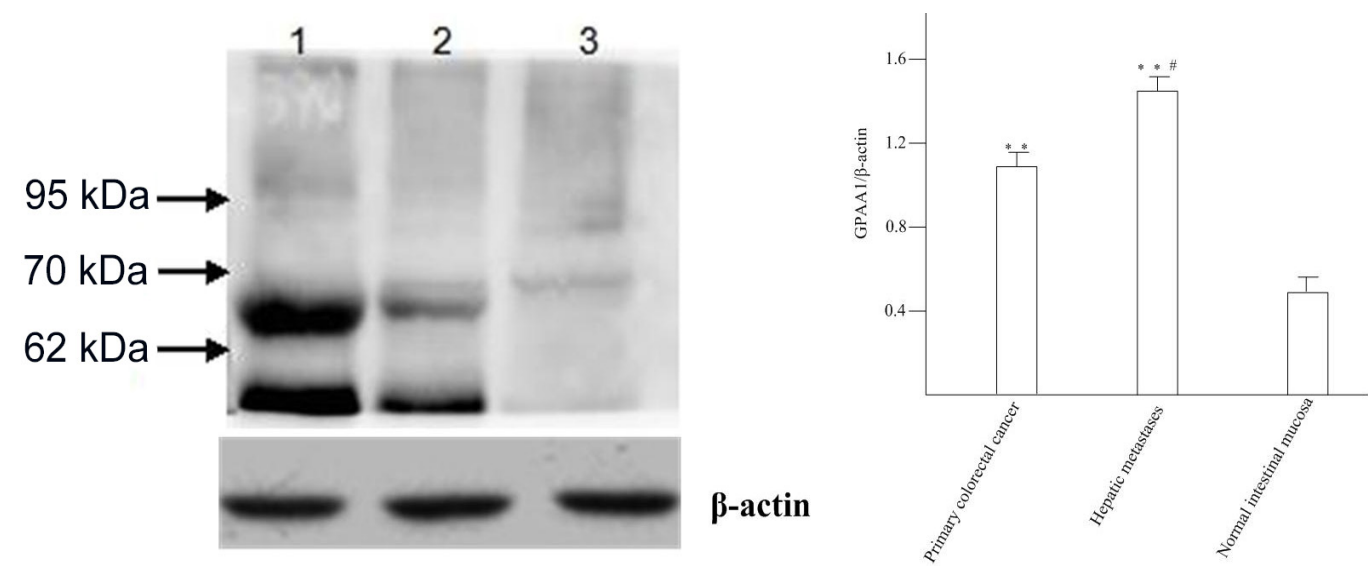

Figure 3. Expression of GPAA1 protein. Lane $1=$ Hepatic metastases; lane 2 = primary colorectal cancer; lane 3 $=$ normal colonic mucosa. ${ }^{* *}$ and ${ }^{*} \mathrm{P}<0.01$ compared to normal colonic mucosa.

\section{Results of the cell invasion assay}

The number of cells $\mathrm{High-GPA}_{\text {of }}$ penetrating the Matrigel membrane was $12.9 \pm 2.4$, which was significantly higher than that of cells Low-GPAA1 $(7.7 \pm 2.1)$, and the difference was statistically significant $(t=3.3541, \mathrm{P}<0.05)$ (Figure 4$)$.

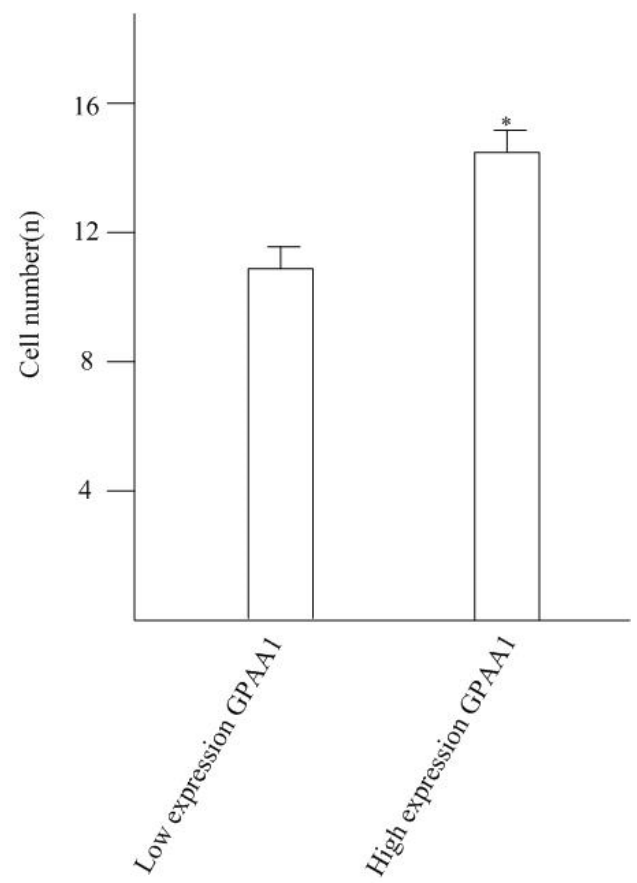

Figure 4. Results of cell invasion assay. ${ }^{*} \mathrm{P}<0.05$ compared to low expression GPAA1. 


\section{Results of co-immunoprecipitation and MALDI-TOF/TOF-MS}

As shown in Figure 5, both the high and low expression GPAA1 groups expressed a protein between 70 and $62 \mathrm{kDa}$. The results of MALDI-TOF/TOF-MS confirmed the identity of this protein.
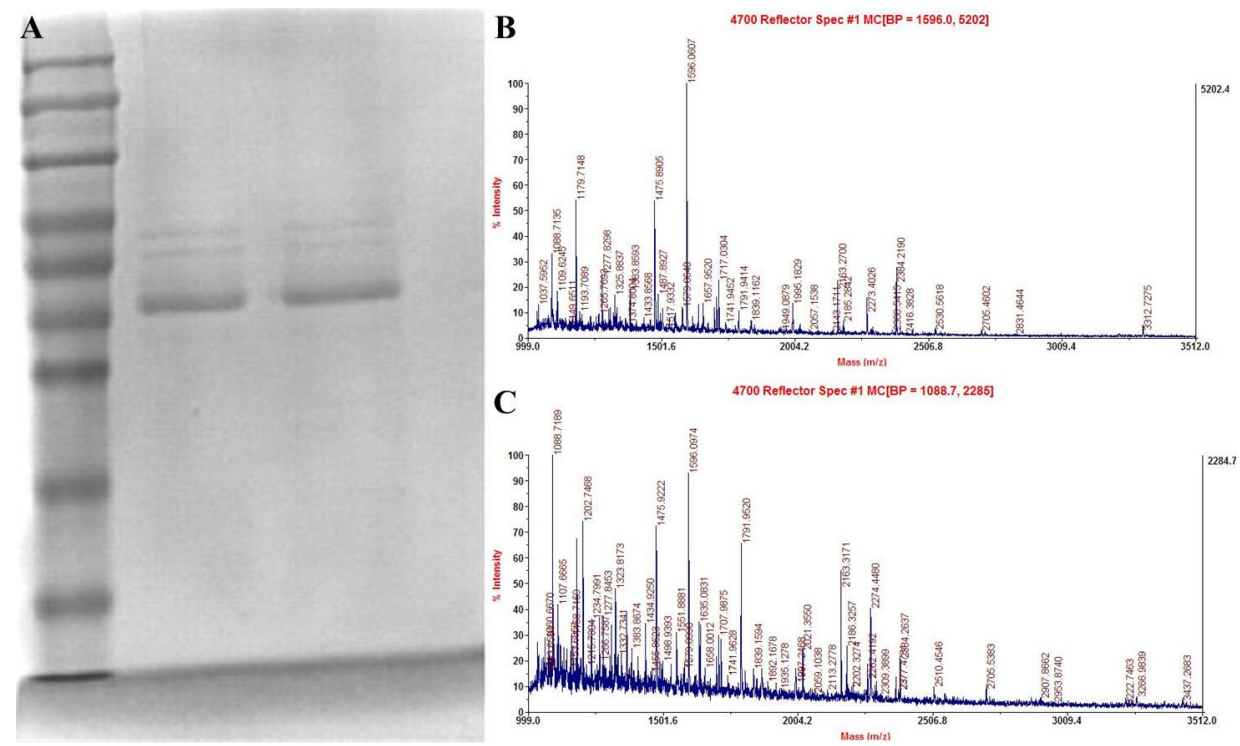

Figure 5. Results of coimmunoprecipitation and MALDI-TOF/TOF-MS.

\section{Relationship between GPAA1 gene expression and pathological characteristics of colorectal cancer}

According to the ratio of GPAA1 mRNA expression in colorectal tumor tissues and normal colorectal mucosa tissues, 52 samples were assigned to two groups: the high-expression group ( $\mathrm{N}$ $=31)$ and the low-expression group $(\mathrm{N}=21)$. The expression level of GPAA1 mRNA was closely correlated with the differentiation degree, but not with age, gender, or Dukes staging (Table 1).

Table 1. Relation between GPAA1 mRNA expression and clinical characters of patients with colorectal cancer.

\begin{tabular}{|c|c|c|}
\hline & High expression of GPAA1 mRNA $(\mathrm{N}=31)$ & Low expression of GPAA1 $\mathrm{mRNA}(\mathrm{N}=21)$ \\
\hline Age & & \\
\hline$>60$ & 8 & 7 \\
\hline$\leq 60$ & 23 & 14 \\
\hline Gender & & \\
\hline Male & 25 & 16 \\
\hline $\begin{array}{l}\text { Female } \\
\text { TDD }\end{array}$ & 6 & 5 \\
\hline $\begin{array}{r}\text { TDD } \\
\text { HD }\end{array}$ & & \\
\hline $\begin{array}{l}\text { HD } \\
\text { MD }\end{array}$ & 5 & $10^{*}$ \\
\hline LD & $\begin{array}{l}11 \\
15\end{array}$ & $4^{7}$ \\
\hline Dukes stage & & \\
\hline A-B stage & 12 & 11 \\
\hline C-D stage & 19 & 10 \\
\hline
\end{tabular}




\section{DISCUSSION}

The glycosylphosphatidylinositol-anchored protein (GPI-AP) is a protein anchored at the surface of the eukaryotic cell membrane through the carboxyl terminus of GPI, which plays an important role in immune recognition, as a complement regulator, and in transmembrane signal transduction. The GPAA1 complex is composed of an anchor attachment protein and GPI, which is an important part of the glycosylphosphatidylinositol transamidase complex (GPIT), which is itself composed of 5 subunits: PIG-U, PIG-T, GPAA1, PIG-S, and GPI (Fraering et al., 2001; Ohishi et al., 2001; Vainauskas et al., 2002; Vainauskas and Menon, 2004). Nagpal et al. (2008) reported that the subunits of GPIT were increased in a variety of tumors. For example, PIG-U was expressed in bladder cancer as an oncogene, and PIG-T and GPAA1 were expressed in breast cancer (Wu et al., 2006). The enhanced expression of GPIT subunits was associated with the proliferation and invasion of tumor cells.

In this study, we detected the expression of GPAA1 with immunohistochemistry, realtime quantitative PCR, and Western blot analysis. The results showed that the expression of GPAA1 was higher in primary colorectal cancer tissues and liver metastasis tissues than in normal mucosa tissues, suggesting that GPAA1 plays an important role in tumor occurrence and development. Our results also showed that the high expression of GPAA1 mRNA was related to the degree of tumor differentiation. Tumors with poor differentiation are strongly aggressive; therefore, this result indicated that the high expression of GPAA1 mRNA was related to tumor invasion, and the expression of GPAA1 in liver metastasis confirmed this view. In addition, the in vitro invasion assay showed that more cells with high expression of GPAA1 penetrated the Matrigel membrane compared to cells with low expression of GPAA1. All of these results showed that the enhanced expression of GPAA1 was closely associated with the occurrence, invasion, and metastasis of colorectal cancer.

GPAA1 is located in human chromosome 8q24.3, and the oncogene c-myc is located in chromosome 8q24.1. The c-myc gene is activated through chromosomal translocation rearrangement, combines with chromosomal DNA, and plays a role in cell growth, differentiation, and malignant transformation (Chana et al., 2002). Amplification of the c-myc gene was also observed in human colon cancer (Sánchez-Pernaute et al., 2005). As the GPAA1 and c-myc genes are located in the same chromosome, both of their expressions were enhanced in colorectal cancer, and the c-myc gene is the target gene of the Wnt signaling pathway (Behrens and Lustig, 2004; Chen et al., 2009). We speculate that GPAA1 might regulate c-myc gene expression through the Wnt signaling pathway. Our study will provide a new foundation and method for the treatment of colorectal cancer; however, the mechanism of GPAA1 effects on tumor proliferation and invasion still needs further study.

\section{ACKNOWLEDGMENTS}

Research supported by the research grant \#30772118 from National Natural Sciences Foundation of China, Beijing.

\section{REFERENCES}

Behrens J and Lustig B (2004). The Wnt connection to tumorigenesis. Int. J. Dev. Biol. 48: 477-487. 
Chana JS, Grover R, Tulley P, Lohrer H, et al. (2002). The c-myc oncogene: use of a biological prognostic marker as a potential target for gene therapy in melanoma. Br. J. Plast. Surg. 55: 623-627.

Chen DH, Wang SM and Chen YW (2009). The changes and and roles of Wnt signaling pathway in colon cancer patients. China Pract. Med. 4: 11-12.

Chen G, Cai HY, Wei XJ, Bai X, et al. (2011). Study on primary cell culture of gastroenteric cancer tissues after cryopreservation. Clin. J. Med. Offic. 39: 606-607.

Fraering P, Imhof I, Meyer U, Strub JM, et al. (2001). The GPI transamidase complex of Saccharomyces cerevisiae contains Gaa1p, Gpi8p, and Gpi16p. Mol. Biol. Cell 12: 3295-3306.

Ho JC, Cheung ST, Patil M, Chen X, et al. (2006). Increased expression of glycosyl-phosphatidylinositol anchor attachment protein 1 (GPAA1) is associated with gene amplification in hepatocellular carcinoma. Int. J. Cancer 119: 1330-1337.

Nagpal JK, Dasgupta S, Jadallah S, Chae YK, et al. (2008). Profiling the expression pattern of GPI transamidase complex subunits in human cancer. Mod. Pathol. 21: 979-991.

Negus RP and Balkwill FR (1996). Cytokines in tumour growth, migration and metastasis. World J. Urol. 14: 157-165.

Ohishi K, Inoue N and Kinoshita T (2001). PIG-S and PIG-T, essential for GPI anchor attachment to proteins, form a complex with GAA1 and GPI8. EMBO J. 20: 4088-4098.

Sánchez-Pernaute A, Pérez-Aguirre E, Cerdán FJ, Iniesta P, et al. (2005). Overexpression of c-myc and loss of heterozygosity on 2p, 3p, 5q, 17p and 18q in sporadic colorectal carcinoma. Rev. Esp. Enferm. Dig. 97: 169-178.

Vainauskas S and Menon AK (2004). A conserved proline in the last transmembrane segment of Gaal is required for glycosylphosphatidylinositol (GPI) recognition by GPI transamidase. J. Biol. Chem. 279: 6540-6545.

Vainauskas S, Maeda Y, Kurniawan H, Kinoshita T, et al. (2002). Structural requirements for the recruitment of Gaa1 into a functional glycosylphosphatidylinositol transamidase complex. J. Biol. Chem. 277: 30535-30542.

Wu G, Guo Z, Chatterjee A, Huang X, et al. (2006). Overexpression of glycosylphosphatidylinositol (GPI) transamidase subunits phosphatidylinositol glycan class T and/or GPI anchor attachment 1 induces tumorigenesis and contributes to invasion in human breast cancer. Cancer Res. 66: 9829-9836.

Zuo FY, Li SY, An P, Yu B, et al. (2004). The construction of yeast two-hybrid method in the protein-interactions and its significance in hepatic metastasis of colorectal carcinoma. Zhonghua Wai Ke. Za Zhi. 42: 672-674.

Zuo FY, Li SY, An P, Yu B, et al. (2006). Screening of proteins in teract with Fasl and its significance in colorectal carcinom a metastasis. China J. Mod. Med. 16: 32-36. 